\title{
Peripheral Clocks: Keeping Up with the Master Clock
}

\author{
E. KowAlSKA AND S.A. BROWN \\ University of Zurich, Institute for Pharmacology and Toxicology, \\ 8057 Zurich, Switzerland
}

\begin{abstract}
Circadian clocks influence most aspects of physiology and behavior, so perhaps it is not surprising that circadian oscillators exist in nearly all mammalian cells. These cells remain synchronized to the outside world in hierarchical fashion, with a "master clock" tissue in the suprachiasmatic nucleus of the hypothalamus receiving light input from the retina and then conveying timing information to "slave" clocks in peripheral tissues. Recent research has highlighted both the similarities and differences between central and peripheral clocks and provided new insight into their communication. Above all, however, this parallelism of clockwork has provided a unique opportunity to study at the cellular level a regulatory mechanism that affects complex behaviors.
\end{abstract}

\section{INTRODUCTION}

In most organisms, circadian rhythms have a key role in the regulation of numerous aspects of physiology and behavior. The circadian clock can be found in organisms ranging from cyanobacteria to complex vertebrates such as mouse and zebra fish. Although the evolutionary advantage of maintaining such a molecular clock is still controversial, it is clear that it confers a fitness advantage for some simple organisms under selective pressure. For example, cyanobacteria that possess an oscillator with a period length tuned to their environment easily outgrow those that do not (Woelfle et al. 2004), and the endogenous period length of wild fruit flies has been shown to change with latitude (Costa et al. 1992). In more complex organisms, mutations in clock genes can lead to cancer and infertility (Fu et al. 2002; Miller et al. 2004) and are correlated with various depressive and sleep disorders (Cermakian and Boivin 2003). It is unclear, however, whether these phenotypes are related directly to the clock or to other functions of clock genes.

At least in metazoan organisms, the circadian clock was for a long time believed to be a complex neuronal phenomenon. A central clock tissue - the suprachiasmatic nucleus ( $\mathrm{SCN}$ ) of the brain hypothalamus in mammals, the pineal gland in birds and reptiles, and the lateral neurons of Drosophila - was believed to synchronize circadian processes throughout the body via presumably electrical cues to other brain regions. The first evidence that these cues might be primarily hormonal in nature came from pioneering work by Silver et al. (1996), who showed that an implanted SCN encased in porous plastic material could rescue the circadian rhythms of an SCNlesioned animal. Other experiments revealed that the basis of this clock is actually cell-autonomous and nonelectrical (Welsh et al. 1995).

Soon afterward in 1997, S.A. Kay's group showed that in D. melanogaster, explanted parts of the body possess independent photoreceptive circadian clocks (Plautz et al. 1997). Cell-autonomous circadian clocks were operative throughout the body. Even serum-shocked immortalized rat fibroblasts, isolated over 35 years previously, were observed to have circadian expression of clock genes (Balsalobre et al. 1998). Subsequent experiments with transgenic Per1::luciferase rats showed that these clocks in fact exist in most tissues of the mammalian body (Yamazaki et al. 2000).

Many further investigations by numerous laboratories have demonstrated that the molecular principle of circadian clocks in metazoans is probably based on interlocking negative transcriptional feedback loops within the cell (Bell-Pedersen et al. 2005). In simpler organisms, each cell-autonomous clock is individually light-sensitive and is therefore independently entrained by the environment. In mammals, however, this synchronization happens in strictly hierarchical fashion to ensure that clocks throughout the whole organism remain properly synchronized. First, an external timing cue (principally light) sets the phase in the central pacemaker, the SCN. This bilateral nucleus contains several thousand independently cycling but locally coupled neurons. Subsequently, the SCN projects its rhythms onto cell-autonomous clocks of similar mechanism in peripheral tissues. The result is synchronous circadian transcription in peripheral tissues with a constant phase delay compared to the SCN (Fig. 1).

\section{COMMUNICATION BETWEEN CENTRAL AND PERIPHERAL OSCILLATORS}

Despite increasing knowledge of the mechanism of the circadian clock and its entrainment, the way in which it controls circadian physiology and gene expression is far from clear. The basic signaling between the core oscillator and peripheral clocks probably involves a mixture of direct hormonal cues such as glucocorticoids and indirect cues such as cyclic body temperature and food metabolites (Damiola et al. 2000; Le Minh et al. 2001; Stokkan et al. 2001; Brown et al. 2002). Although each of these cues can phase-shift peripheral oscillators without affecting the central clock in the SCN, the elimination of the circadian pattern in any one of these signals does not result in the loss of peripheral circadian gene expression. Hence, 


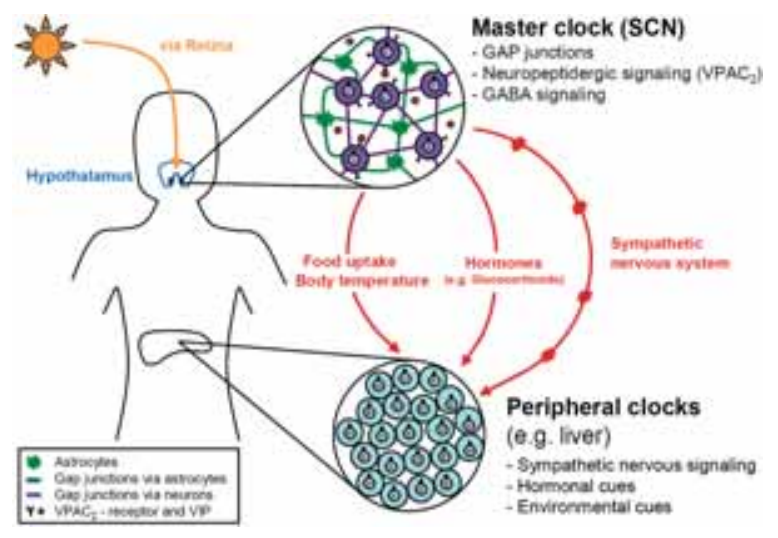

Figure 1. A model for clock hierarchy in mammals. (Red) Connections between different body clocks and their influence on other oscillators. In the hypothalamus (blue), the master clock sitting in the SCN is composed of pacemaker neurons (purple) which are interconnected and synchronized by neuropeptidergic signals and/or gap junctions via astrocytes (green) or neurons (purple). Light perceived via the retina and downstream signaling through the retinohypothalamic tract ( yellow), is responsible for adjusting clock phase in the pacemaker neurons. In peripheral clocks (light blue), as an example the liver clockwork, entrainment is mainly dependent on SCN downstream signaling via the sympathetic nervous system, hormones, and environmental cues (e.g., glucocorticoids).

each of these signals is either redundant or unimportant to circadian synchrony in vivo.

Recent research has even challenged the established hierarchy between the core oscillator and peripheral clocks. For example, the expression of the clock gene Per 1 could be directly induced in the adrenal gland via light in an SCN-dependent mechanism, suggesting the existence of a "shortcut" directly from light to some peripheral clocks. An intact sympathetic nervous system was essential to this process (Ishida et al. 2005). Tissue-specific clock disruptions have confirmed the existence of such direct circuits. Genetic disruption of circadian rhythms in liver results in the abolition of circadian transcription of some liver genes, but not of others, including the clock gene Per2 (Kornmann et al. 2007). Similarly, the section of the vagus nerve resulted in elimination of oscillations both in Per 2 expression and in acetylcholine receptor protein levels in the respiratory tract (Bando et al. 2007).

The current working model for circadian clocks is thus a multifaceted one in which the SCN communicates with peripheral oscillators via several pathways. These peripheral oscillators can in turn directly control circadian genes either via transcription factor cascades or via the same cisacting elements that control clock genes in general. Finally, some further peripheral circadian gene expression and physiology appears to be controlled not by peripheral clocks, but directly by the SCN via nervous stimuli.

\section{SIMILARITIES AND DIFFERENCES BETWEEN CENTRAL AND PERIPHERAL OSCILLATORS}

Considerable speculation has centered on the fundamental nature of clock architecture in SCN neurons and in other tissues. The same basic oscillator components exist in both central and peripheral oscillators, and both are capable of robust cell-autonomous oscillations. Most genetic mutations that affect central oscillator function have similar qualitative effects upon peripheral oscillators (Yagita et al. 2001; Pando et al. 2002). Nevertheless, these effects are often exaggerated in peripheral oscillators, pointing to possible differences. For example, deletion of the Perl gene results in a shortening of the circadian period of behavior by 1 hour, but the period of circadian gene expression in isolated $\mathrm{Perl}^{-/-}$fibroblasts is 4 hours shorter (Brown et al. 2005b).

One possible reason for this difference could arise at the level of expression of clock components themselves. For example, it has recently been shown that deletion of the important circadian transcriptional activator CLOCK in mice does not abolish circadian behavioral rhythmicity (Debruyne et al. 2006). These authors speculate that in the $\mathrm{SCN}$, the function of CLOCK can be substituted by the NPAS2 protein (Debruyne et al. 2007). Because NPAS2 shows a tissue-specific expression pattern, one might suppose that explanted peripheral tissues that do not express NPAS2 would be severely attenuated even though the SCN was not.

Another obvious difference between SCN and peripheral oscillators is that whereas explanted SCN oscillators appear to possess the ability to continue oscillations indefinitely, oscillators in explanted peripheral tissues dampen rapidly (Yamazaki et al. 2000; Yoo et al. 2004). In principal, this experimental observation could arise either through attenuation of clock oscillations in each cell or via gradually increasing desynchrony among clocks in adjacent cells due to differences in cellautonomous endogenous period length. Fluorescent or bioluminescent imaging of fibroblast cells in culture firmly supports the latter hypothesis: Individual fibroblasts show long-duration circadian oscillations (each of slightly differing period) but fail to synchronize to one another without external stimuli (Nagoshi et al. 2004; Welsh et al. 2004). Although fibroblasts in culture clearly lose synchrony, the same question is less clear in vivo. Confirming the in vitro experiment above, SCN-lesioned hamsters show constant, intermediate levels of clock genes in peripheral organs, an observation that implies cellular desynchrony within each organ (Guo et al. 2006). In contrast, SCN-ablated mice after several days display large phase differences in individual tissues of an animal and among different animals, suggesting the opposite (Yoo et al. 2004).

This discrepancy aside, the clearly superior synchrony among SCN neurons compared to peripheral cells and tissues is likely the result of better intercellular coupling, rather than greater clock precision. Dissociated SCN neurons, like fibroblasts, demonstrate significant heterogeneity in period length and phase (Welsh et al. 1995, 2004). In intact SCN tissue, three clearly defined intercellular coupling methods exist: gap junctions, peptidergic signaling using the VIP neuropeptide and the VPAC2 receptor, and GABA signaling. Elimination of either of these first two pathways results in significant circadian impairments in vivo (Liu and Reppert 2000; Harmar 2003; Long et al. 2005; Maywood et al. 2006). 
Current views divide the SCN into at least two functional suboscillators: the dorsal SCN and the ventral SCN. Interrupting the connection between them results in loss of synchrony in the dorsal part of the SCN but leaves the ventral part perfectly synchronized (Yamaguchi et al. 2003). It is thought that the ventral SCN receives timing information from the retinohypothalamic tract and subsequently communicates this information to the dorsal SCN neurons. Such a bipartite organization might further stabilize SCN oscillation.

Altogether, experimental evidence and mathematical modeling suggest that intercellular coupling could explain the resistance of the SCN-and by inference circadian behavior - to mutations that more severely attenuate peripheral oscillators of similar molecular makeup (Bernard et al. 2007; Liu et al. 2007).

\section{PERIPHERAL OSCILLATORS AS PROBES OF CIRCADIAN CLOCK FUNCTION}

Differences in both clock gene expression and intercellular coupling likely exist between peripheral and central oscillators. Nevertheless, self-autonomous peripheral clocks could provide an important model system for the elucidation of many aspects of clock function that are more difficult or impossible to study in the central SCN oscillator itself, especially in human beings. In principle, peripheral clocks provide two advantages over the study of the whole organism or of the central clock in the SCN: accessibility to experimental manipulation and availability in homogeneous large quantities. Multiple laboratories have exploited these aspects for both biochemical and genetic studies into the mammalian circadian oscillator.

For example, by labeling the clock protein PER1 with peptide epitopes and then expressing it in fibroblasts, our laboratory was able to purify a PER 1 -containing protein complex that contained cryptochromes (proteins previously identified as important to clock function), as well as two other novel proteins, WDR5 and NONO. Fibroblasts were then used as easy model systems in which to study the function of these two proteins. RNA interference (RNAi)-based knockdown of NONO protein levels demonstrated NONO to be essential to circadian rhythms in these cells, and knockdown of WDR5 demonstrated that this protein was necessary for histone methylation at circadian clock loci (Brown et al. 2005a).

Of course, the observation that WDR5 and NONO are important to clock function in fibroblasts does not permit an immediate generalization to the whole organism. The final "acid test" of validity remains the analysis of the whole organism. Usually, this test is performed via a mouse knockout model. Such a knockout is generated by homologous recombination in embryonic stem (ES) cells, which are then injected into a mouse blastocyst to create a chimera - a time-consuming and costly process. Because these ES cells are pluripotent, their differentiation into other cell types that exhibit circadian rhythmicity permits the rapid screening of generated cells for circadian phenotypes, at least if the targeted gene has a phenotype at the heterozygous or hemizygous level. Coupled with "gene-trap" approaches to generate non- functional alleles, such an ES cell differentiation approach could be used as a rapid screen for new X-linked clock genes (E. Kowalska and S.A. Brown, unpubl.).

Fibroblast oscillators have also been used as functional tools to identify the underlying mechanism of human mutations that cause circadian disorders. For example, familial advanced sleep phase syndrome (FASPS) has been mapped in one family to a point mutation in the Per 2 locus (Toh et al. 2001). By expressing the mutant allele in fibroblasts, Vanselow et al. (2006) were recently able to characterize the nature of this defect at a molecular level, as well as to recapitulate the advanced phase of the behavioral phenotype of this mutation by measuring the transcriptional phase of FASPS fibroblast cells under entrained conditions.

\section{OUTLOOK: POTENTIAL USES OF PERIPHERAL CLOCKS TO CHARACTERIZE HUMAN DISORDERS}

Such an application of peripheral cells to verify or study human phenotypes could potentially impact patient care and diagnosis in a clinical setting. Although the human circadian oscillator has been characterized extensively at a behavioral level, the difficulty and cost of maintaining subjects under controlled conditions to effect these measurements prevent their widespread use. Easily available peripheral tissues (blood, skin, hair) could provide a useful proxy. Primary cells from these tissues can be infected with lentiviral or adenoviral reporter vectors that permit bioluminescent readout of circadian gene expression, thereby enabling the investigator to monitor different properties of the molecular clock and characterize its function (Brown et al. 2005b).

For such studies to be possible, it is important to establish the relationship between circadian properties measured in peripheral tissues such as fibroblasts and those measured via human behavior. Although initial studies have shown excellent correlations between behavior in mice and the molecular properties of fibroblasts, further studies in human beings are necessary to validate these conclusions. Fibroblast period length per se is influenced by culture conditions such as temperature and the concentration of serum in their growth medium. Nevertheless, cells displaying short- and long-period lengths seem to retain their relative values under all conditions (Fig. 2). Thus, although comparisons of values from different laboratories may prove problematic, the assay as a whole shows great promise.

Specifically, peripheral oscillators as a model system might permit screening of patients with sleep disorders to determine which are due to molecular defects in the circadian clock. When peripheral cell cultures are kept under constant growth conditions, an estimate of free-running period length can be obtained. By placing them in entrained conditions - e.g., 24-hour temperature cyclesone can then look at entrained phase. It will be interesting to see how both of these properties correspond to behavior in human subjects. Finally, by using these properties as quantitative traits in human pedigrees or populations, genetic linkage or association studies should be possible, 

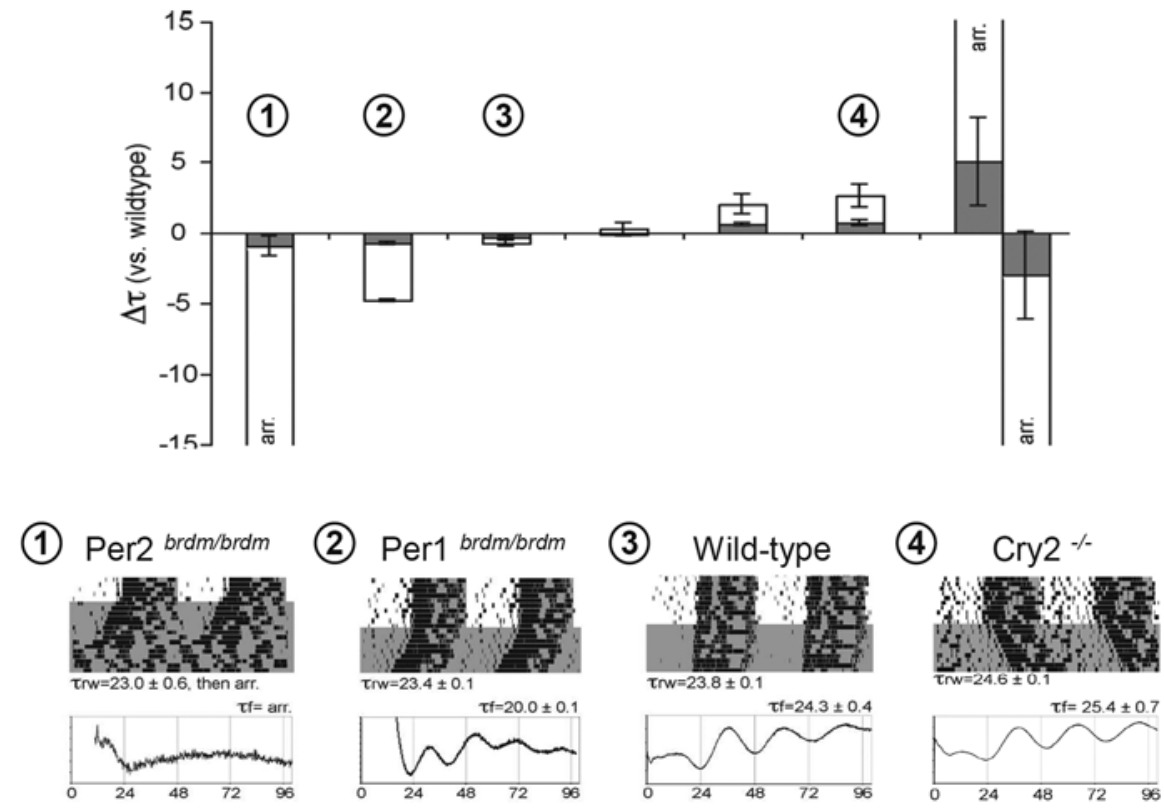

Figure 2. Genotypic variation of period lengths in different mutant backgrounds. The variation of circadian period length measured from fibroblasts (white bars) is compared to behavioral period length measured via running-wheel activity data (light gray bars), expressed as difference in hours from the 24-hour light cycle. (Top panel) Genotypes shown from left to right: Per ${ }^{\text {brdm/brdm }}$,

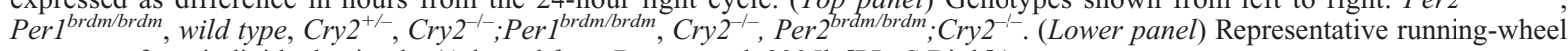
actograms from individual animals. (Adapted from Brown et al. 2005b [PLoS Biol.].)

enabling the discovery of modifier loci for human chronotype.

Recent studies all highlight the extent to which circadian clocks impact not only behavior, but also cellular processes such as cell division and metabolism. Peripheral oscillators could also provide an excellent model system in which to study these phenomena-for example, the involvement of the circadian clock in DNAdamage checkpoint control, whose disregulation leads to cancer (Collis and Boulton 2007). Further investigations will undoubtedly ascertain not only the potential, but also the limits of this exciting model system.

\section{ACKNOWLEDGMENTS}

The authors would like to thank L. Cuninkova and A. Dumas for their helpful commentary regarding this manuscript. Work herein from the authors' laboratory was in part supported by grants from the Swiss National Science Foundation, EUClock, and the Desiree and Neils Yde Foundation.

\section{REFERENCES}

Balsalobre A., Damiola F., and Schibler U. 1998. A serum shock induces circadian gene expression in mammalian tissue culture cells. Cell 93: 929.

Bando H., Nishio T., van der Horst G.T., Masubuchi S., Hisa, Y., and Okamura H. 2007. Vagal regulation of respiratory clocks in mice. J. Neurosci. 27: 4359.

Bell-Pedersen D., Cassone V.M., Earnest D.J., Golden S.S., Hardin P.E., Thomas T.L., and Zoran M.J. 2005. Circadian rhythms from multiple oscillators: Lessons from diverse organisms. Nat. Rev. Genet. 6: 544.
Bernard S., Gonze D., Cajavec B., Herzel H., and Kramer A. 2007. Synchronization-induced rhythmicity of circadian oscillators in the suprachiasmatic nucleus. PLoS Comput. Biol. 3: e68.

Brown S.A., Zumbrunn G., Fleury-Olela F., Preitner N., and Schibler U. 2002. Rhythms of mammalian body temperature can sustain peripheral circadian clocks. Curr. Biol. 12: 1574

Brown S.A., Ripperger J., Kadener S., Fleury-Olela F., Vilbois F., Rosbash M., and Schibler U. 2005a. PERIOD1-associated proteins modulate the negative limb of the mammalian circadian oscillator. Science 308: 693.

Brown S.A., Fleury-Olela F., Nagoshi E., Hauser C., Juge C., Meier C.A., Chicheportiche R., Dayer J.M., Albrecht U., and Schibler U. 2005b. The period length of fibroblast circadian gene expression varies widely among human individuals. PLoS Biol. 3: e338.

Cermakian N. and Boivin D.B. 2003. A molecular perspective of human circadian rhythm disorders. Brain Res. Rev. 42: 204.

Collis S.J. and Boulton S.J. 2007. Emerging links between the biological clock and the DNA damage response. Chromosoma 116: 331.

Costa R., Peixoto A.A., Barbujani G., and Kyriacou C.P. 1992. A latitudinal cline in a Drosophila clock gene. Proc. Biol. Sci. 250: 43 .

Damiola F., Le Minh N., Preitner N., Kornmann B., FleuryOlela F., and Schibler U. 2000. Restricted feeding uncouples circadian oscillators in peripheral tissues from the central pacemaker in the suprachiasmatic nucleus. Genes Dev. 14: 2950 .

Debruyne J.P., Weaver D.R., and Reppert S.M. 2007. CLOCK and NPAS2 have overlapping roles in the suprachiasmatic circadian clock. Nat. Neurosci. 10: 543.

Debruyne J.P., Noton E., Lambert C.M., Maywood E.S., Weaver D.R., and Reppert S.M. 2006. A clock shock: Mouse CLOCK is not required for circadian oscillator function. Neuron 50: 465

Fu L., Pelicano H., Liu J., Huang P., and Lee C. 2002. The circadian gene Period 2 plays an important role in tumor suppression and DNA damage response in vivo. Cell 111: 41.

Guo H., Brewer J.M., Lehman M.N., and Bittman E.L. 2006. 
Suprachiasmatic regulation of circadian rhythms of gene expression in hamster peripheral organs: Effects of transplanting the pacemaker. J. Neurosci. 26: 6406.

Harmar A.J. 2003. An essential role for peptidergic signalling in the control of circadian rhythms in the suprachiasmatic nuclei. J. Neuroendocrinol. 15: 335 .

Ishida A., Mutoh T., Ueyama T., Bando H., Masubuchi S., Nakahara D., Tsujimoto G., and Okamura H. 2005. Light activates the adrenal gland: Timing of gene expression and glucocorticoid release. Cell Metab. 2: 297.

Kornmann B., Schaad O., Bujard H., Takahashi J.S., and Schibler U. 2007. System-driven and oscillator-dependent circadian transcription in mice with a conditionally active liver clock. PLoS Biol. 5: e34.

Le Minh N., Damiola F., Tronche F., Schutz G., and Schibler U. 2001. Glucocorticoid hormones inhibit food-induced phaseshifting of peripheral circadian oscillators. $E M B O J . \mathbf{2 0}$ : 7128.

Liu A.C., Welsh D.K., Ko C.H., Tran H.G., Zhang E.E., Priest A.A., Buhr E.D., Singer O., Meeker K., Verma I.M., Doyle F.J., III, Takahashi J.S., and Kay S.A. 2007. Intercellular coupling confers robustness against mutations in the SCN circadian clock network. Cell 129: 605 .

Liu C. and Reppert S.M. 2000. GABA synchronizes clock cells within the suprachiasmatic circadian clock. Neuron 25: 123.

Long M.A., Jutras M.J., Connors B.W., and Burwell R.D. 2005. Electrical synapses coordinate activity in the suprachiasmatic nucleus. Nat. Neurosci. 8: 61.

Maywood E.S., Reddy A.B., Wong G.K., O’Neill J.S., O’Brien J.A., McMahon D.G., Harmar A.J., Okamura H., and Hastings M.H. 2006. Synchronization and maintenance of timekeeping in suprachiasmatic circadian clock cells by neuropeptidergic signaling. Curr. Biol. 16: 599.

Miller B.H., Olson S.L., Turek F.W., Levine J.E., Horton T.H., and Takahashi J.S. 2004. Circadian clock mutation disrupts estrous cyclicity and maintenance of pregnancy. Curr. Biol. 14: 1367.

Nagoshi E., Saini C., Bauer C., Laroche T., Naef F., and Schibler U. 2004. Circadian gene expression in individual fibroblasts: Cell-autonomous and self-sustained oscillators pass time to daughter cells. Cell 119: 693 .

Pando M.P., Morse D., Cermakian N., and Sassone-Corsi P. 2002. Phenotypic rescue of a peripheral clock genetic defect via SCN hierarchical dominance. Cell 110: 107.

Plautz J.D., Kaneko M., Hall J.C., and Kay S.A. 1997.
Independent photoreceptive circadian clocks throughout Drosophila. Science 278: 1632.

Silver R., LeSauter J., Tresco P.A., and Lehman M.N. 1996. A diffusible coupling signal from the transplanted suprachiasmatic nucleus controlling circadian locomotor rhythms. Nature 382: 810.

Stokkan K.A., Yamazaki S., Tei H., Sakaki Y., and Menaker M. 2001. Entrainment of the circadian clock in the liver by feeding. Science 291: 490.

Toh K.L., Jones C.R., He Y., Eide E.J., Hinz W.A., Virshup D.M., Ptacek L.J., and Fu Y.H. 2001. An hPer2 phosphorylation site mutation in familial advanced sleep phase syndrome. Science 291: 1040.

Vanselow K., Vanselow J.T., Westermark P.O., Reischl S., Maier B., Korte T., Herrmann A., Herzel H., Schlosser A., and Kramer A. 2006. Differential effects of PER2 phosphorylation: Molecular basis for the human familial advanced sleep phase syndrome (FASPS). Genes Dev. 20: 2660.

Welsh D.K., Logothetis D.E., Meister M., and Reppert S.M. 1995. Individual neurons dissociated from rat suprachiasmatic nucleus express independently phased circadian firing rhythms. Neuron 14: 697.

Welsh D.K., Yoo S.H., Liu A.C., Takahashi J.S., and Kay S.A. 2004. Bioluminescence imaging of individual fibroblasts reveals persistent, independently phased circadian rhythms of clock gene expression. Curr. Biol. 14: 2289.

Woelfle M.A., Ouyang Y., Phanvijhitsiri K., and Johnson C.H. 2004. The adaptive value of circadian clocks: An experimental assessment in cyanobacteria. Curr. Biol. 14: 1481.

Yagita K., Tamanini F., van Der Horst G.T., and Okamura H. 2001. Molecular mechanisms of the biological clock in cultured fibroblasts. Science 292: 278.

Yamaguchi S., Isejima H., Matsuo T., Okura R., Yagita K., Kobayashi M., and Okamura H. 2003. Synchronization of cellular clocks in the suprachiasmatic nucleus. Science 302:1408 Yamazaki S., Numano R., Abe M., Hida A., Takahashi R., Ueda M., Block G.D., Sakaki Y., Menaker M., and Tei H. 2000. Resetting central and peripheral circadian oscillators in transgenic rats. Science 288: 682.

Yoo S.H., Yamazaki S., Lowrey P.L., Shimomura K., Ko C.H., Buhr E.D., Siepka S.M., Hong H.K., Oh W.J., Yoo O.J., Menaker M., and Takahashi J.S. 2004. PERIOD2: LUCIFERASE real-time reporting of circadian dynamics reveals persistent circadian oscillations in mouse peripheral tissues. Proc. Natl. Acad. Sci. 101: 5339. 


\section{$8_{\mathrm{CSH}}^{\infty} \mathrm{C}$ Cold Spring Harbor Symposia SYMPOSIA on Quantitative Biology}

\section{Peripheral Clocks: Keeping Up with the Master Clock}

E. Kowalska and S. A. Brown

Cold Spring Harb Symp Quant Biol 2007 72: 301-305

Access the most recent version at doi:10.1101/sqb.2007.72.014

References This article cites 38 articles, 13 of which can be accessed free at: http://symposium.cshlp.org/content/72/301.full.html\#ref-list-1

\section{License}

Email Alerting

Receive free email alerts when new articles cite this article - sign up in the box at the Service top right corner of the article or click here.

To subscribe to Cold Spring Harbor Symposia on Quantitative Biology go to: http://symposium.cshlp.org/subscriptions 